\title{
Current Status of Hearing-Impaired Children in Reading Picture Books With Their Parents in China: Comparison With Normal Hearing Children
}

\author{
Wenqing Mao $^{1 *}$, Satoe Saigusa ${ }^{1}$, Inho Chung ${ }^{2}$ \\ ${ }^{I}$ Graduate school of Comprehensive Human Sciences, University of Tsukuba, Tsukuba, Japan \\ ${ }^{2}$ Faculty of Human Sciences, University of Tsukuba, Japan \\ *Corresponding author. Email: wenqingmao@tsukuba.ac.jp
}

\begin{abstract}
So far, a lot of research on how hearing children read picture books with parents at home has been done. However, there is no detailed information concerning how children with hearing impairment read picture books with their parents at home and why parents read picture books to their hearing-impaired children. This study investigated the current status of children with hearing impairment reading picture books with their parents in China and what types of thoughts parents have toward reading picture books, and comparing this to hearing children. 88 parents of hearing-impaired children aged 3 to 5 and 107 parents of hearing children aged 3 to 5 answered a questionnaire concerning how their children read picture books at home and their thoughts on reading picture books. Results showed that children with hearing impairment read picture books with parents once a week at home for 5 to 15 minutes each time, starting later and less frequently than hearing children. When reading picture books, parents of hearing children pay more attention to practicing their children's language and hearing, improving their children's imagination and ensuring a reading environment. On the other hand, it suggests that parents of hearing-impaired children don't read in a variety of ways and don't make much effort to give their children full reading. Moreover, compared with parents of hearingimpaired children, parents of hearing children have a strong desire to increase their children's knowledge and communication skills by reading picture books.
\end{abstract}

Keywords: reading picture book, children with hearing impairment, china

\section{INTRODUCTION}

So far, a lot of research on how hearing children read picture books with parents at home has been done. However, there is no detailed information concerning how children with hearing impairment read picture books with their parents at home and why parents read picture books to their hearing- impaired children. Grasping the current situation of children with hearing impairment reading picture books with their parents and parents' thoughts on reading picture books is conducive to providing more effective educational supports.

The purpose of this study was to clarity the current situation of children with hearing impairment reading picture books with their parents and parents' thoughts on reading picture books.

\section{METHOD}

Participants : 88 parents of hearing-impaired children aged 3 to 5 were randomly selected from a special education school and two rehabilitation centers in China. 107 parents of hearing children aged 3 to 5 were randomly selected from the normal kindergarten in China.

Questionnaire items :

1.The items about the current situation of children with hearing impairment reading picture books (1) When did the child start reading picture books(2) Frequency of reading picture books( 3 ) Length of reading (4)Who read together with your child(5) Type of picture books(6) Things to try with your child(15 items) Participants gave rankings on a five grade evaluation for 15 questionnaire items.

(1) (5) was given 1-5 or 1-6 points. Referring to previous study (Chen \& Motegi \& Chung, 2015),15 items were classified into four categories as Things to try to help children understand the picture books, Things to try to practice the language, Things to try to improve the children's imagination, Things to try to ensure a reading environment.

2.The items about parents' thoughts on reading picture books. (1) Purpose of reading picture books (15 items). Participants gave rankings on a five-grade evaluation for 15 questionnaire items. Referring to previous study 
(Chen \& Motegi \& Chung, 2015),15 items were classified into five categories as To increase knowledge, To improve communication skills, To enhance curiosity and anticipation, To stabilize children's mood, To enhance parent-child relationship.

Table 1 The current status of children with hearing impairment reading picture books

\begin{tabular}{lcccc}
\hline & Max & 3 age & 4 age & 5 age \\
\hline Age to start reading & 6 & $2.97(0.66)$ & $2.43(0.57)$ & $2.59(0.83)$ \\
Frequency of reading picture books & 5 & $2.42(0.85)$ & $2.39(0.69)$ & $2.66(0.97)$ \\
Length of reading & 5 & $2.16(0.78)$ & $2.46(0.64)$ & $2.62(0.62)$ \\
\hline
\end{tabular}

Table 2 The current status of hearing children reading picture books

\begin{tabular}{lcccc}
\hline & Max & 3 age & 4 age & 5 age \\
\hline Age to start reading & 6 & $4.21(0.91)$ & $4.00(1.05)$ & $3.88(1.06)$ \\
Frequency of reading picture books & 5 & $3.12(1.25)$ & $3.06(0.98)$ & $3.01(0.83)$ \\
Length of reading & 5 & $2.32(0.84)$ & $2.19(0.82)$ & $2.44(0.96)$ \\
\hline
\end{tabular}

(2) What are the things to keep in mind when reading picture books with your child (free description).

\section{RESULT AND DISCUSSION}

The current status of children with hearing impairment reading picture books with their parents.

Average points and SD for each questionnaire items are shown in Table 1 and Table 2. We used KruskalWallis test to clarify the age change. According to Kruskal-Wallis test, significant differences in reading time were found between the children with hearing impairment aged 3 and aged 4 groups $(\mathrm{p}<.01)$, the children with hearing impairment aged 3 and aged 5 groups $(\mathrm{p}<.01)$, and the children with hearing impairment aged 4 and aged 5 groups $(p<.05)$. We used Mann -Whitney test to clarify the difference between the hearing-impaired children and hearing children. According to Mann-Whitney test, significant differences in reading initial age and frequency of reading picture books were found between the hearing-impaired children and hearing children $(\mathrm{p}<.01)$. Results showed that children with hearing impairment read picture books with parents once a week at home for 5 to 15 minutes each time, starting later and less frequently than hearing children. When reading picture books, parents of hearing children pay more attention to practicing their children's language and hearing, improving their children's imagination and ensuring a reading environment.

Parents' thoughts on reading picture books.

To clarify the changes of parents' thoughts on reading picture books as their child grows up, we used Kruskal-Wallis test. According to Kruskal-Wallis test, significant differences in [to increase knowledge], [to improve communication skills] were found between children aged 3 and aged 4 groups $(\mathrm{p}<.05)$, children aged 3 and aged 5 groups(p<.05), and children aged 4 and aged 5 groups $(\mathrm{p}<.05)$.It suggests that both parents of hearing-impaired children and parents of hearing children want to increase children 's knowledge and improve communication skills by reading picture books. The result is nearly the same as shown by Ishigawa(2011) .

We used Mann -Whitney test to clarify the difference between the hearing-impaired children and hearing children. Compared with parents of hearing-impaired children, parents of hearing children have a strong desire to increase their children's knowledge and communication skills by reading picture books.

\section{CONCLUSION}

The conclusion of this research is that there is a significant difference between hearing-impaired children and normal hearing children in reading picture books. The parents of hearing-impaired children don't read in a variety of ways and don't make much effort to give their children full reading. While, the parents of hearing children have a strong desire to increase their children's knowledge and communication skills by reading picture books.

\section{REFERENCES}

[1] Akita,K. \& Muto,T.(1996)Why do mothers read picture books to their children?-Mothers 's conceptions and their setting environment on reading-.Japanese Journal of Educational Psychology,44,109-120. (in Japanese)

[2] Chen, Y. \& Motegi, M.\& Chung,I.(2015) Utilization of Picture Booksfor Children with Hearing Impairments in the Hearing Impairment Kindergarten Classroom. Hearing and Language Disorder,42,31-41.(in Japanese)

[3] DeTemple, J., \& Snow, C. E.(2003)Learning words from books. On reading books to children, 16-36.

[4] Ishigawa,Y.(2011) A study of picture book as artifact: through a survey of mothers' expectation for the picture books pertaining to cognitive development in children. The Journal of Seigakuin University 24(1), 75-88. (in Japanese) 